\title{
Virtual Reality as Technology
}

\author{
Yengin D. ${ }^{1}$ \\ ${ }^{1}$ Deniz YENGiN, Istanbul Aydin University, (Turkey) \\ e-mail: denizyengin@aydin.edu.tr
}

\begin{abstract}
While technology is transforming itself from tool to aim, machines started to use individuals. The machines that are being developed to facilitate human life have become indispensible for individuals' lives because of the advantages they offer. This approach, which is the mile stone of technological determinism, is changing the relation between the technology and the machine, and the relation between humans and machines. In this study, through the questions "Is technology a machine or are humans machines?" human's and technology's future is reviewed with a critical approach and discussed with a recommended model. According to this approach, human develops the machine that facilitates his/her life and then depends on that machine emotionally and continues his/her life with it. This emotional commitment helps the human produce continuously. Behaving so, the human tries to improve the life by enabling the machine to serve more advantageous features. With today's technology, human's approach to virtual reality, and hence to technological determinism has changed and at this point it turned out to be the cause of the virtual determinism's occurrence. Now the human, who has adopted a lifestyle interpenetrated with virtual reality, has demanded technology to improve this way and with the user-base for virtual reality googles spreading he/she has had the chance to live different experiences. In a virtual world, individuals who have experienced the data which have been coded and designed beforehand like it was real, are able to play games, design, communicate, and do shopping, watch news in places where they cannot be in real life. If it is briefly stated they do most of the activities they can and can't do in their real lives. This situation increases human's demand towards virtual reality, canalizes technology's development in this direction, and with this developing technology, human's evolution accelerates. As a result of this, technology's benefits increases thanks to virtual reality glasses. In this context, throughout the study, virtual reality technology is observed. With a group of twelve children aged 9 to12, an experiential study is conducted with virtual reality glasses. A chosen Playstation4 Pro VR themed game was played by the children who participated in the study, and their reactions are recorded then their attitudes towards virtual reality were analyzed by measuring the game's real-time image and the child's reactions to it.
\end{abstract}

Keywords: technology, virtual reality, virtuality

\section{Introduction}

The technique is an extension of human's war against nature. While discovering the laws of nature, human used a tool which is especially made or thought for that discovery. Every single tool represents a technique. The term technique represents a tool in the meaning of the knowledge of getting and producing things. The term technology, which is the result of technique, is the socializing process of this knowledge and it's getting a social meaning. Briefly, technology is socialized information. According to Ellul, technique doesn't resemble other things but only itself. It changes the things it touches but it is untouchable. Technique; doesn't respect anything, adore anything, on the contrary it turns everything it touches into a slave. Besides, the only important things for technique are product and production. Human really participates in economy but technique makes him participate in economy like a thing not like human. (Ellul, 2003: 23-32). Technique means doing a radical change in production. Technique, which is produced by humans on purpose, changes the technology and creates a techno-copy of human life. In this context, humans try to live under pressure after turning into technological beings. Technique categorizes human as consumer and raises the pace of producing and consuming simultaneously. Now, with the technological knowledge they gained, human 
who has begun to earn the status of a techno-social life, is in a hurry to increase production capacity by accelerating consumption. Its main reason is the push of technology and because of this push, human wants to be in a constant state of consumption (Dijk, 2016: 192). Individual, who cannot detach himself/herself from consumption behavior, is now in the position of strict meta follower in monopoly of technique. Human, who doesn't satisfy just with this, sends the technical content he has obtained to individuals who are at the same level of context decoding like him. People, who find useful and take pleasure from the functionality of meta, are creating a community and being involved in a technosocial life, they demand the updated technique in advance when it is updated. Today new media technologies can be given as an important example of the only thing technique cares about is product and production. The reason of this is the human, who is under pressure because of technique, does not find the conventional media sufficient and that's why he develops new media technologies with the help of internet in a short time. Thanks to these technologies, human, who is involved in every moment of technology, can suppress his fear of technology's push by constant stream of information media provides. As a result of the socialization of the produced information, human, who is globalized, starts to become digitized technically as a techno-social life individual. The relationship between individual and technique constantly updates itself with the help of productive development provided by the technology, now it isolates the digitized individual and discards the unified consumption. Hence technique -with the help of new media technologies- guides people and makes them consume updated Meta. Because humans have become the subject of techno-social life, they are faced with the mechanical slavery. In mechanical slavery, human now becomes a gear of production and integrates with the technology and is complementary to the system (Lazzarato, 2015: 25). In this context, towards the functionality of technique the machine, as a product of human, is developed to meet consumer needs. However, it also shapes the person who produces it in the direction of its existence and canalizes his/her consumption habits. This functionality of technique strengthens the relationship between human and machine and also forces the people to demand the up-dated information by exposing non-technical functional commodities. Thus, techno-social life is constantly oppressed with knowledge. Cluster of bits (binary digit) -representing the lowest units of information- are specifically chosen for the technique required for his life and with the rise of technology, individuals become a member of techno-social life -and gaining the title of user- by paying a fee. Techno-social life is a reflection of social life, so it metamorphoses with the virtual identity in people's new media technology. Thanks to the ability of remaining hidden in digital media, people can be involved in the consumption lines that they cannot include in real society life and they can spread the knowledge they have without being limited by any censorship. In this context, the user who discovers the libertarian side of technosocial life, with his new virtual identity, adds new innovations to the lots of information he has and in this way he helps technique to increase its impact on people.

According to Selçuk Artut, the technology shaped in the light of technical knowledge, represents the spirit of materiality. Because of this materiality, people need assistant technologies. Because the human has turned into an individual of techno-social life, he/she uses technology at every moment of his life. The main reason for this is that human memory is not adequate for the human. Mankind does not use the power of their memory and for this they support their memory with assistant technology. However, the external mind is ruining the human's life and excessive adverse effects are seen. As a result, people are becoming slaves of technology. (Artut, 2014: 47-48). For example, an individual is used to living with a smart phone. When he is left without it, he feels stressed and problems are seen in the functioning of his life because he has left his habit of living with the external mind. From this point of view, as a slave of technology and living in a techno-social life, human tries to update the technique and ensure the environments that the technique cannot be abandoned.

Human, who is an individual of techno-social life and who has become a part of this life by creating a techno-copy of his/her real life, has passed a new phase where virtual reality and his/her real life are intertwined. Human, who has begun to live in the digital environment of McLuhan's famous rhetoric "Global Village", has had a chance to make clear action from many dangerous outcomes in real life, has created a great demand by purchasing the produced meta (as digital game, $3 \mathrm{~d}$ movie etc.) with this content. Virtual reality products that have become a giant budget market, continues to develop and spread in the direction of human demands. At this point, virtual reality glasses, one of the technological developments for improving the human relation with virtual reality, have become a part 
of this. The virtual reality environment, in which a techno-copy of every object in real life is designed and built, deepens the techno-social perception of society through virtual glasses. Only through his/her eyes, human, by renewing the perception of reality $s /$ he's in, begin to experience the virtual environment integrated with the relation of technique and simulation. In this sense, the relationship between technique and simulation must be examined in order to analyze virtual reality technology.

\section{Technique and Simulation in Techno-Social Life}

Thinkers like Harold Adam Innis and Marshal McLuhan, who examine the transformation of technology in society's life and have a technological approach in this sense, claim that in technologies developed for the sake of communication, change and development, alter people's thinking, preferences and lives. These two thinkers see the technology, which is regarded as the world's problem solver, as a transformer of the society, servant for the sovereign powers and a technique that provides constant potential for change. In this context, technical knowledge has mediated the integration of the simulation with technology. Television, one of the first channels of media in which the relationship of technique and simulation emerges, forms a cultural consensus on the nature of reality. It includes individuals to the social hegemony by enculturating them to the system of dominant values. It influences behavioral patterns of everyday life by redefining individuals' identities, status and roles and role expectations. In this sense, cultural hybridization plays a dominant role, including the society in techno-social life. The media uses the technique for enculturation of individuals into the system of dominant values and the postmodernism tendencies that become widespread through cultural industries and they are strengthened by the communication. By the help of this, intercultural communication, cultural mutations and crossbreeding are roundabout (Önür, 2012: 282-288). For television, which is one of the most common tools of traditional media, television companies must constantly produce media products. For this reason, in order to meet the ever-increasing demand, systems that enable to watch television broadcasts via internet collectively emerged. As these systems give birth to new methods for watching serials, they are also developed for the desire of individuals to control what, where, when, and by which methods they want to watch. Thanks to Netflix, Hulu and Amazon Video, where they can watch series and films, in addition tools like Apple TV and Amazon Fire TV, people in the United States have the habit of binge watching. Binge watching, is defined as "multiple video and series watching in a situated position or for a specific period of time" (Turgut, 2013) and is one of the signs of techno-social life. "Binge watching" concept, conveyed by Serdar Turgut, helps to explain the propagation of metas forming content for virtual reality. Dubbed "binge consumption", this user habit can be expressed as an indication of consumption of metas produced for virtual reality as well as being consumed by the user. Thanks to internet, its sharing speed has increased considerably. This speed encourages the user to have the habit of binge consumption. In this consumption phase, the user makes the binge consumption popular by converting the traditional media to the users of the producers in terms of the freedom of decisionmaking and the approach of usages and gratifications, which leads to increase of consumption all the time. In this sense, the techno-social community intensifies the demand for technological meta consumption. From the point of view of the relationship between technique and simulation, Jean Baudrillard's simulation theory sheds light on the concept of binge consumption and therefore technosocial society. According to Baudrillard, simulation represents the consumption of reality through models in a way that lacks an origin or a reality. Reality has an operational view. Therefore, it cannot even be seen as real, because there is functionality that bundles up the thing perceived as reality. Deprived of all kinds of imaginary and real distinctions in the later phases of history, it is possible to talk about a hyper reality that refreshes itself through existing models and does nothing but produce a differential simulation. According to Baudrillard, things continuously try to produce their twins. They are in such a state that, their purpose became repeating instead of renewing and twin codes take place of the originals. In this sense, the simulation is completely contrary to the utopia of equality principle and does not accept the indicator as a value. This also means that simulation and re-animation should not be confused with each other. The simulation transforms the entire regeneration scheme into a simulacrum (appearance which wants to be perceived as a reality). In virtual reality the simulation supports binge consumption and therefore techno-social life is made up of factored models that cover even the most unimportant events. According to this, it is difficult to talk about an absolute reality, as well as to talk about the production of an illusion. Because there is no such a thing called real anymore and reality has disappeared. This situation causes an aggressive attitude in the structure of the 
simulation that replaces the reality; the simulation is always about attacking reality. What causes this is the unresponsiveness of the truth that is surrounding the human being against the simulation. Thus it is now impossible to isolate the process of production of the truth and to prove the truth. The simulation is trying to replace reality with this aggressive attitude and to explain that the human surroundings are in fact nothing more than a simulation. Because, there is nothing that truth can do against the power of the simulation's repetitive reputation. This short circuit to reality is something that is reproduced through the demonstrations. This is nothing but giving a simulated look to the truth. This also suggests that the simulation is always more effective than the truth (Baudrillard, 2016). The simulation, which forms the basic logic of the metas created for virtual real world, simulates the real life area of human and makes human part of the techno-social life. Human, who has the aim of perfecting his/her habitat, by overcoming the rigorous material production with simulation, he places the virtual metas, produced in a much shorter time and in a cheaper way, in the living space. In this sense, virtual reality technology is being developed specifically to enable people to have the metas that they can design and integrate into real life space by using simulation. With the participation of virtual intelligence in the history of humanity, where the difference between reality and simulation never disappears so far, technology serves to create more effective and more pleasant forms of social control and social cohesion for the people's lives (Marcuse, 2015: 14). However, simulation, which has taken reality's place, transforms technology with a deterministic approach. The mechanization, which is the result of the technology, is observed as a facilitator for human life, increasingly reduces the quantity and intensity of the bodily energy consumed in labor (Marcuse, 2015: 37). However, this does not change the way people see virtual reality technology and the developments in this technology are increasing day by day. Virtual reality, which transforms the people's need for communication in the form of virtual interaction, has lost the battle it had with simulation as Baudrillard said. From now on there is no return from virtual real world, which has blended with the simulation that has therefore entered human life, through the virtual intelligence, to the purely real world-based models. Human wanted to transform the social life, which s/he lives in, into a techno-social life.

\section{Virtual Reality as Technology}

New Dynamics are emerging as a result of the life struggle that human gives against nature and his surroundings. Over time, these Dynamics have begun to become a constant part of human being. Technique and technology phenomena are also indicative of these dynamics. To meet the requirements the information produced by trial-and-error method, is now described as technique, and extension is described as technology. According to Atabek, technique is "knowledge of getting something", and technology is "the socialization of this knowledge we produce, and have a social value". Techniques in communicative events have taken physically permanent places. In this war of existence, the concept of technique has first started to become a stockholder of individuals, then society, and of global concern. The technique that exists with the cultures of society is indispensable from today's life. Technology is an organ that passes down with culture and is expressed and used by production (Eriksen, 2015: 313). Technology has formed a dynamic and permanent structure with the relation between technique and economy. Technology reveals man's struggle against nature and his production process, and thus emerges the formation of human's social relations and the mental designs that arise from them (Mosco \& Fuchs, 2014: 152). At this point it has become important to define the economy, the politics of economy and the system of capitalism. Capitalism centralizes the economy as a system in which the capital is the main production purpose, where the means of production are private property owned and controlled, the economic activities are carried out in order to gain profits, and the property belongs to capital owners (Odyakmaz \& Acar, 2008: 71). In this context, the economy is subjected to regulations which aim at maintaining and improving the functioning of capitalism. The economic system, which is embraced with technique, designs the technology in order to shape the consumer society and canalize the society's demands. In this case, technically equipped people are trying to maintaining the economy politics in favor of the existing order by producing machines and also reducing the time spent for production. As a result, human, who applies technology in every aspect of life in mechanical slavery, maintains the capitalist capital flow for the sake of this slavery tradition. "Mechanical slavery takes the place of "human slavery" regime of the old imperial systems (Egypt, China, etc.) and therefore it is the mode of command, regulation and canalization supported by technology, in this state it represents one of the freedoms of capitalism" (Lazzarato, 2015: 25). The person, shaping his lifestyle with mechanical slavery, uses the mass media 
and new media technologies when s/he wants to get the updated technique. But sources of information have always been monopolized throughout history. Formatted and specially designed information is directing the individual users and it determines the developmental course of technology. But the informational monopolies will eventually be condemned. Because humans also want to get involved in the formation of knowledge as they are the recipients of knowledge. In this context, "informational monopolies have been partly developed and collapsed, on the medium of communication tools they are built upon; as they emphasize religion, local governance, time or power, centralization, and place, they tend to do that in sequence" (Innis, 2006: 248).

In the United States, it is considered as the origin of mechanical slavery concept, when the root of the concept is searched out it is seen that, a great breakthrough was made after the industrial revolution, and sometimes communication devices, which are used for the purpose of monopolizing information, have many effects. Thanks to the power of mechanical communication systems, the United States has financed a new type of imperialism, in which its sovereignty is protected and imperialism has expanded, and it has succeeded in using this system (Innis, 2006: 252). In this regard, the United States has designed the technique to provide continuity, has dismissed technology's anti-continuity features. Today's up-to-date technological developments (Apple products, Microsoft products, software programs, Google, etc.) also prove this. In terms of technique, production and consumption are expected to take place in a balanced manner. However, when the demand and production are not balanced, the technique interferes with production and tries to repair the distorted balance in terms of mechanical operation and continuity. For this reason, producers fulfill the necessity of mechanical slavery by destroying excess production when if it is needed (Smith \& Evans, 2016: 39).

After the Industrial Revolution, technique, which plays a major role in transforming technology from tool to aim, carries out this activity under human control. However, technology, which is a human production, has brought about the problems of dependency. Disorders that target the mental health of people, called Nomo phobia and Netlessphobia have reached worrisome dimensions. Nomo phobia is the concern of the lack of a mobile phone which is the result of the development of smart phones and integration with the internet. Netlessphobia is the fear of not having an internet. These two disorders severely threaten an individual's health profile and cause traumatic reactions like mental breakdown. In this context, rehabilitation centers have been established in many countries. The aim of the centers is to protect and treat the individuals against the adverse effects of internet and mobile phone. When we look at it, it seems that the technology of human production has made the human being into a mechanical slave that needs to be treated. Although the technique seems to be taking some measures against the impaired mental health (like in Apple's current phones, switching to the night mode), the number of individuals complaining of discomfort such as Nomo phobia and Netlessphobia is increasing day by day.

This aggressive attitude of technique is the essence of the repression that the simulation implements to the reality. This pressure, which drags the human being to the mechanical slavery, is again an invention of human, and this pressure creates a sense of virtual reality that human always wants to take part in. However, the basis of this problem is necessity and the necessity is the main reason of invention (Basalla, 2013: 18). Technique covers the human being in the light of the necessity and it reveals a state of lack of freedom. This situation is kind of a lack of freedom that means a person submits himself to the tool he produced (Marcuse, 2015: 43). Simulation, which is developed with technique, creates a universe that surrounds the human being by simulacrums and spreads the belief that these are the human needs within this universe. Human misunderstands that he has a wide variety in these requirements. Besides this, technique, using the fact that the simulation can suppress the truth, always looks for ways to improve, for this reason, human develops technique, hence simulation, as if producing for his requirements. Therefore, simulation transforms human life by eliminating the differences between reality with great appetite and is the essence of virtual reality technology.

Virtual reality technology is a world created by human in terms of functioning. This world seems to offer a wide variety of products with the producers leading. However, this diversity exploits human in every sense because it is a diversity that takes shape in the context of technological determinism. Because virtual reality technology is a world that people created with their own hands, as 
always the things that human produces preserves its presence, innovation becomes a fundamental part of the world that human builds up with his own hands (Basalla, 2013: 47). In this context innovation is a very important element for the virtual reality's existence. Virtual reality technology, like the labor that has been shown to be a traditional media tool for television, is constantly in need of production. This production has been incorporated into a capital system that does not allow for a moment to stop. The main reason for this is the infinite demand wave against production, which is intertwined with technology. Basalla indicates that technology is as old as human history (Basalla, 2013: 50). In this context, human beings, which have a close relationship throughout history with technology, use technology to transform the living space and to make a techno-copy of it. Technological tools have been invented so that the created virtual reality can be observed.

Virtual reality glasses have been developed in a short time and have been spread by users. In addition, these glasses are the latest technology in which human can find the opportunity to observe human life space as a techno-copy in the virtual real world. Human beings are positioned in the analytical space through visual perception. The brain relies on the physical conditions through the body's eyes and allows the person to establish a physical balance in these conditions. In this sense, human beings can sustain their life by associating the magnetic field of the world with the visual perception. This situation also effects human emotionally. According to this, the mental state of a person changes in proportion to the environment in which he is. The light, color and form that the environment has, transforms the human being by causing changes in emotional reactions, so that the brain manages desires and needs towards human perception. The visual perception that is the basis of all this management is used by blending technique with technology. In this context, technology responds to inventions that people have dreamed of and virtual reality is one of those demands. At first, in the direction of human demands, the transformation of the media has evolved from one-way communication to two-way communication and has continued to be shaped by transforming media technologies into modern media. Virtual reality has evolved and its evolution has accelerated in the development of the opportunity to create a virtual identity in Web 2.0 technology that emerged during the transformation of media.

A virtual reality glass is used to make the screen image provided by smart phones, computers, consoles and many other technological devices produced with technologies such as LCD, LED, which are widely used today, more realistic. Because of the natural lapses of the human eye, the image that is perceived more realistically by the human brain forms the basic working principle of the virtual reality glass. Virtual reality glasses, the technological invention designed to influence the visual perception of the human brain, are evaluated in three environments. These are partially participatory environments, fully participatory environments and common (multiple) participatory environments. 


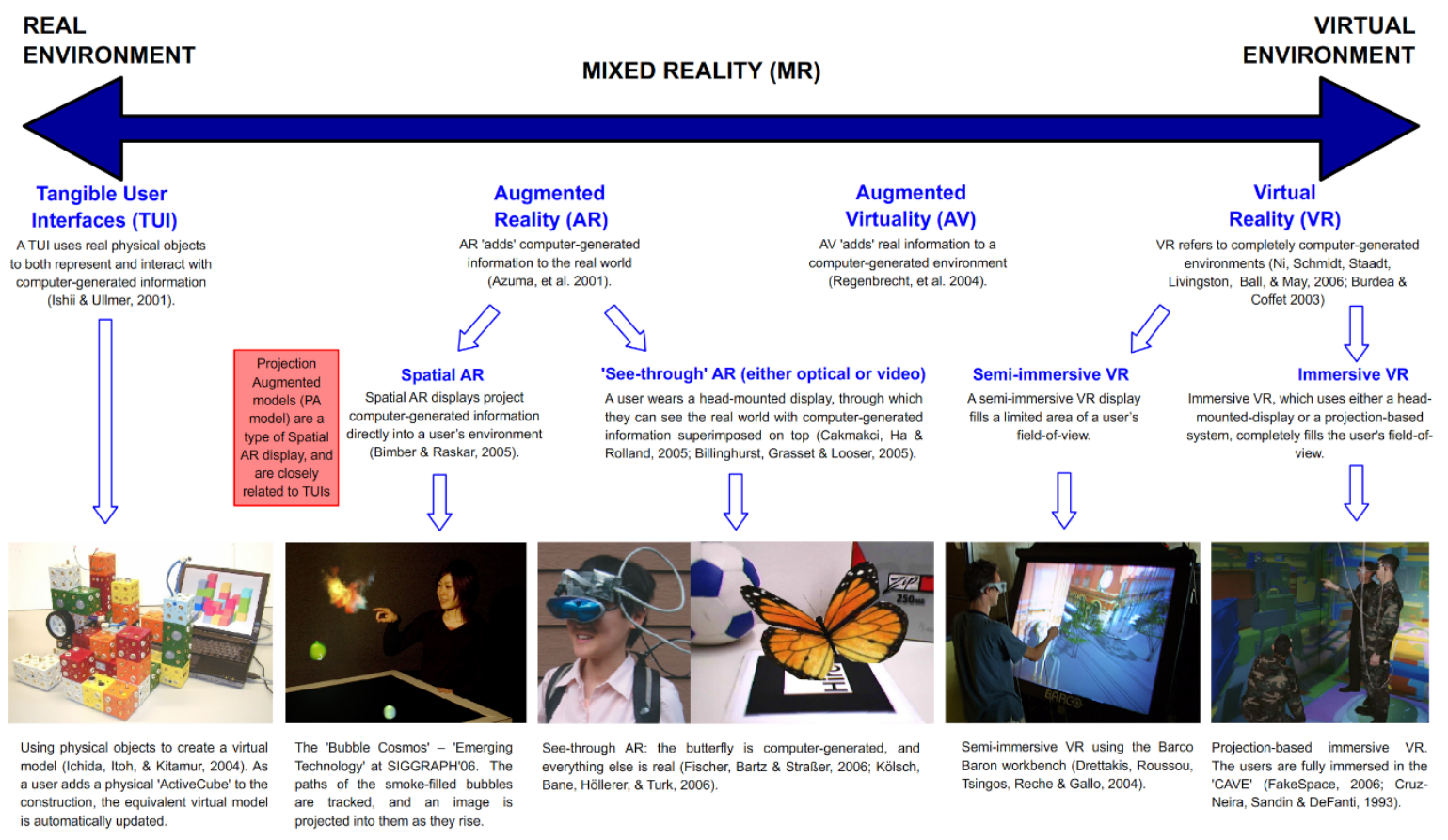

Figure 1. Virtual reality and Real Environment Relations

Reference: goo.gl/ESqRSN

All these environments are equipped with the content supported by Web 3.0 technology, which has come to life after Web 2.0 technology. Based on the interaction of the artificial intelligence with the user, the process that the user applies on the techno-copy image is transferred to the real item as design. For example, 3D printers that allow three dimensional design, with the help of virtual reality glasses and dermal-tactile perception device, designed by a designer who designs it as a technocopy, offers the opportunity to materialize the product. Thanks to the virtual reality technology which evolved in this context, reality's techno-copy design, which came to life with Web 2.0 technology, process has begun to reverse. An object that does not exist in real life can be designed as a technocopy by means of virtual reality technology and can be materially combined through three-dimensional printers.

Virtual reality (VR) technology allows users to experience interactive, fully fledged experiences that appeal to all of their senses. Thanks to this technology, the user thinks that $s /$ he is in a different environment through visual perception. VR technology consists of a set of technologies aimed at convincing the user that the virtual reality world in which the individual is deceived as their senses are actually a part of the virtual reality world. In this regard, Intel's Virtual Reality Center Excellence Manager Kim Pallister notes the fact that computer-based platforms, including virtual reality technology, cause people to renew themselves is a very interesting development (1- goo.gl/XiNYXa). VR technology consists of large glasses, headphones and position adjuster camber, which are placed in the eyes by means of a cord that generally passes behind the head. In this context, VR technology includes magnifying lenses to enhance visual quality and controls designed to manage that image. In VR technology, instead of looking at a flat screen, the user looks at screens designed for each eye, where the brain brings two images together to form a three-dimensional perception. The visual on the screen where the user looks at fills the entire field of view of the user. The screen, in which the lenses are positioned facing each other, stands in front of the user's head, so that the visual moves with the user, thanks to the positioning feature of the camera placed in front of the user. However, the adequacy of display technology is very important. Today, television technology is broadcasted at thirty frames per second (FPS). However, some designed programs can reach sixty frames per second. The screen used in the VR technology is displayed at a frame rate of 90 to 120 frames in a second. This is a speed that is necessary for the human brain to perceive a visual as reality. With such high levels of speed, the user ensures that the individual is fully engaged and adapts to the virtual reality world. 


\section{Reality-virtuality continuum}

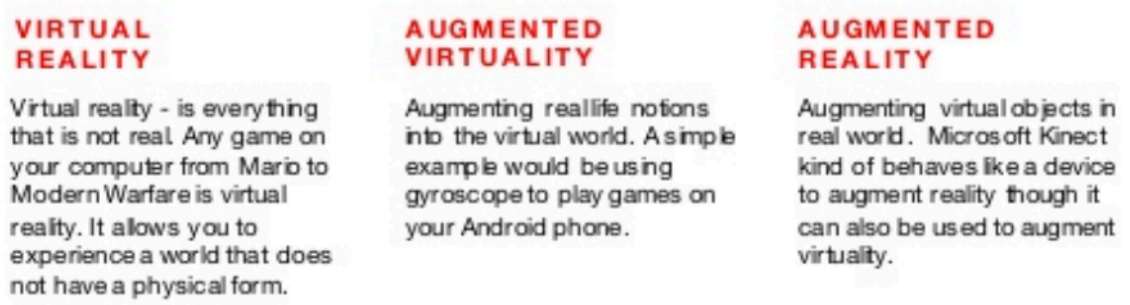

Virtual realty - is every thing that is not real Any game on your compuler from Mario to Modern Warfare is virtual reaity. It alows you to experience a world that does not have a physical form.

\section{VIRTUALITY}

AUGMENTED

Augmenting reallife notions int the virtual world. A s imple example would be using gyroscope to play games on your Android phone.

\section{AUGMENTED \\ REALITY}

Augmenting virtual objects in real world. Micros oft Kinect kind of behaves lke a device to augment reality though it can also be us ed to augment virtualty.

\section{MIXED REALITY}

A mix of virtuality and reality to bemore specific $t$ is a mix of Augmented Reality and Virtual Reality. Microsoft HobLens is perfect example of mixed reality, wherein a user can navigate through real world wth a use of virtual objects and real ife notions such as 'depth' is used on the virtual objects for better experience.

Figure 2. The Process of Virtual Reality Reference: goo.gl/1z1f4h

Pallister states that the first and the most important aspect of this technology is that it offers a 3D image and allows it to change according to the position of the head. Thus, the individual who uses this technology forgets the existence of the virtual reality glasses. Today's virtual reality glasses have screens similar to HD televisions. However, in the light of advancing technology, color and light quality are further improved, frame speed is increased and high-resolution displays with more detail in the image, are possible. In this sense, virtual reality technology, including today's VR technology, requires advanced technical features. For this reason, old computer technology is completely inadequate, and the presence of computer technology supported by new generation processors is very important. Today's technology, where screen quality reaches HD levels, has begun to become obsolete. With advancing technology, the screen quality is expected to reach $4 \mathrm{~K}$ or even $8 \mathrm{~K}$ screens. However, these screens will still need high-end computer technology. The most crucial point of virtual reality technology is that the image is not static and that the technology involved is developed in order to provide users with real-world experience. Some headphones, for example, have motion sensing sensors, which are placed in front of the user and allow the image to remain static. These sensors position the individual in the virtual real world by positioning the user's real position in the analytical space. In this context, the actions that individuals do in real life can be done in the virtual real world with techno-copy images. With the used sensors, the user is simultaneously being monitored by the computer, so that the user gets reaction as if the individual is interacting with the real world.

\section{Methodology}

While technology was changing into the aim rather than a tool, machines started to use human. Machines, which are being developed to make people's lives better, become essential in human's life with the advantages they offer. This approach which is the base of technological determinism, transforms relations between technology and machine and the relation between the human and the machine. In this study, through the questions "Is technology a machine or are humans machines?" human's and technology's future is reviewed with a critical approach and it is discussed with a recommended model. According to this approach, human makes the machine and then he becomes emotionally attached to that machine, which made his life easier, and lives his life with it. This emotional commitment makes human produce continuously. Thus, human tries to develop the machine, which makes his life easier, serve him/her more advantageous features. With today's technology, the individual's approach to the virtual reality, hence his approach to technological determinism has changed and because of its state, technological determinism became the cause of occurrence of the virtual determinism. At last humans who have adopted a life style which embraces 
virtual reality, has demanded technology to improve in this way, with the virtual reality glasses' userbased spreading, had the luck to live different experiences. In a virtual world, individuals who have experienced the data which have been coded and designed beforehand like it was real, can play games, design, communicate, and do shopping, watch news in places where they cannot be in real life. It is briefly stated they do most of the activities they can and can't do in their real lives. This situation increases human's demand towards virtual reality, canalizes technology's development in this direction, with this developing technology human's evolution accelerates. Hence, technology's benefits increase thanks to virtual reality glasses. In this context, throughout the study, virtual reality technology is observed. With a group of twelve children aged 9 to12, an experiential study is conducted with virtual reality glasses. A chosen Playstation4 Pro VR themed game was played by the children, who participated in the study, and their reactions were recorded, then their attitudes towards virtual reality are analyzed by measuring the game's real-time image and the child's reactions to it.

In this part of the study, a pre-test was applied to the focus group comprising of 12 children that were chosen to play soccer game with Playstation VR. In this pre-test, each individual player's soccer knowledge has been measured and information has been provided in advance about the game they are going to play. After the pre-test was completed, the players played the game for one week while they were wearing VR glasses, then their responses and improvements were observed. Thus at what degree they could show their real life abilities on shooting a football in virtual world is monitored.

\section{Focus Group Research Technique}

The research on the effect of virtual reality technology on the users is quite new and although the number of these studies is increasing day by day, they are not adequate. Inadequacies, especially in the academic sense, prevent us from having information about the effects of virtual reality technology on the communication process. It will be possible to understand and follow the severe effects of the developing technology by obtaining the data about how this technology transforms the user. In line with this thought, focus group work has been chosen in order to obtain trustworthy data on virtual reality technology and to place this data on an academic level. This technique was developed by the American sociologist Robert K. Merton. The aim of focus group research technique is to get the individual, who wanted to be interviewed, to be aware of the hypothesis of the search subject and have them interpret via the applied experiments (Duverger, 2014: 294-295). In the focus research technique, the priority information to be acquired is how the subjects feel about the research topic. In addition to this information, it should be known whether the subject of the research has any influence on the life of some of the individuals. Maxfield and Babie stated that focus group discussion should take place in less than 2-3 hours with the participations of 8-15 people. An observer and a reporter should be involved in these interviews and relevant opinions and tendencies should be gathered (Demir, 2014: 307). In short, its aim is to reach knowledge and thought of the participant about the research topic by asking the group questions created according to the hypothesis and goals determined in the focus group research technique.

Focus group study has been conducted in order to be able to observe the effects of virtual reality technology on individuals and to reach trustworthy data. In this study, virtual reality technology Playstation VR, which is located in VRlab laboratories in İstanbul Aydın University New Media Administration and Research Center, was used. Soccer students who participated in the study were tested first and then the Headmaster football game was played on the platform, after the experience, an end test was applied to the participants and the data gathered together. In addition, the study was also broadcast live on YouTube channel New Media IAU.

Nine students attending the Arsenal Soccer School in Turkey participated in the focus study. There were 1 female and 8 male students in the group. One of them is 5 years old and the others are from 9 to 11 years old. In the first test, it was learned that all of the students had their own computers. This means that they are very familiar with computer technology. Students declared that they spend 34 hours, rarely 4-6 hours on computer and they stated that they use their mobile phones more than computers to connect to the internet. From this point of view, it is understood that computers are used for playing games rather than for surfing the internet. Students mostly prefer internet technology to listen to music, watch videos and use social media platforms like Facebook and Instagram. At this point, a striking element is that the students do not prefer social media platforms, such as Twitter, 
where the flow of news is intense. In this context, only one of the students in the group has a Twitter account. The students, who indicated that they use the internet every day, stated that their parents did not have any time restrictions, but they have prohibitions related with the context. It is seen that the families' warning are usually about application purchases.

The students in the group stated that they have been training regularly for 2-3 years and playing soccer. It is understood that the students who stated that they want to be football players in the future have some experience in football. In the first test, students' assumptions were that virtual reality technology would not be sufficient in terms of football experience. Students, who thought that the mechanics of football could only be learned through physical reality, stated that they did not trust the training offered by virtual reality technology. Students in the group stated that they did not experience virtual reality technology before. However, all students have a good command of game consoles. The students stated that they played a console game called FIFA in the game consoles, but the game could not replace reality. Some of the students have reported that their talents will be blunted and even decline if virtual reality technology is used in soccer training and it has been understood that all the students are prejudiced towards virtual reality technology. During the test phase, students played virtual real football game named Headmaster preloaded on Playstation VR platform. This game is a football game powered by the Unity game engine, where the user can fully interact with the virtual ball using head glasses. In order to play the game, the perception camera and virtual reality glasses are needed.

After children experienced virtual reality, they wanted to continue playing and they wanted to try other games as well. They said that this practice, combined with the game of football they enjoyed in their real life, gave them a lot of fun. The students especially mentioned the names and brands of elements such as glasses about virtual reality, when they first saw them. Especially, the PlayStation VR was the most mentioned system. In general, rapid adaptation has seen in the community that sees virtual reality as a game element. It has also been observed that, after wearing glasses, individuals frequently try to touch elements in their surroundings as if they were real. It is noteworthy that students, who have technical knowledge in soccer game, tried target-oriented hitting habits. In addition, there was a general increase in competition and motivation in the group. In the first stage, only those players who tend to score goals strategically developed tactics after a certain period of time, and in this context it is seen that they adjusted their body position. As a result of the application, all of the students asked for information about where they can get the system. However, they declared that the virtual reality is closer to reality than imagination. At the same time, they mentioned that the apparatus such as chest, foot should be attached to the system. It is understood that the learners can develop their ability and habits via the virtual reality system and soccer game in particular. While they were playing football, the group members understood that they were on air, and expressed their wish to follow the YouTube account. The broadcast made students more excited in this context, it is remarkable that they neither felt any alienation nor needed hiding.

\section{Conclusion}

Technology sets the direction of history and defines it. The hypothesis of Innis' "those who possess communication tools, dominate the world" becomes more evident in today's environment. Technology-based communication environments in global culture make it easier for individuals to control the system together with digital transformation. Because the individuals are coded with numbers and represent their selves in the virtual environment. It is a must to use new media at this point. It is imposed to the individual that the logic that there is no place for the people who don't use and learn this new media. Requests, that control the information, occur in work, language and power. Habermas claims that those who have knowledge in this course will govern the society. Technique and science are being canalized according to what ideology desires, and they are produced in this direction because science and technique have become the most important power. Especially science and technology are steadily canalized in developed countries. New technologies are supported, produced and managed by the global system in light of new information. Today, the individual is born as a technocrat. Technology culture guides the individuals to believe in something after they have seen it. This assumption is very dangerous when the information is prepared beforehand and 
ideologically transmitted by someone. In this case it is used to canalize and control rather than informing individuals.

Individuals enjoy using the new media. They are involved in all kinds of activities voluntarily. The individual working in this environment copies what others do. Artificialness is becoming widespread and although things which are done seems like they are original in fact they are ordinary. The monotype society approach that Herbert Marcuse emphasizes, can literally take place with new media. What we believe is chosen by the people who manage the new media and they are presented to masses. Today's society is working for pleasure, entertainment, and being canalized to it because the individual is not shaped by his own decisions, but by the decisions of the global system. As a result of the formatting process, individuals take on features that resemble each other. "Interactive computer networks are shaped by creating new forms of communication and channels, shaping the lives, at the same time being shaped and folded by life" (Castells, 2008, 2-3). According to Elon Musk, artificial intelligence could even be more dangerous than a nuclear weapon. At this point, artificial intelligence products like Apple Siri, Amazon Echo, Microsoft Cortana, Google Now and IBM Watson... will be the future. But it should not be forgotten that these are weapons.

The digital world is being marketed as a meta. The statement, "Digital makes life better than the real", summarizes the environment in which the individual lives. Digital is wanted to be adopted in society. Society, too, sees and uses the good side of digital. That is why the other side of the digital cannot be seen. It has to be left to the individual if he wants to adopt or not. On the contrary, the society is exposed to the phrase "use it or leave here". Digital media makes us transparent. In the approach of Foucault's study "Birth of the Prison", everyone in prison is controlled and monitored. However, the observer and the controlling person are certainly not seen by the individual. At this point, individuals; are easily seen and observed in the virtual world where they are represented by their digital identities. The individual is unaware of the situation in which he lives and in this context the individual is actually living in a fully transparent prison.

The transparent prison environment which the community is not aware of; can be exemplified in the simplest way with the remarkable America's statement in which "We are watching foreigners, not America's American citizens" is stated. The emergence of knowledge that technology giants like Google, Yahoo, Skype, Microsoft and Facebook, have opened up all user information to the state, is just a simple indicator of the digital environment we are in. At this point, it can be clearly seen that the data in the digital environment is watched by those who control these systems. The body is both blessed and inactivated under the obscure shadow of the cyber-space (Bauman, 1998a: 20). According to Bauman, it is now only a matter of seconds to conquer the space that is now not an obstacle. It is difficult to overcome the facts; whereas flow into a digitized environment is as easy as pressing a key.

As Baldini stated in the light of the important information we are describing, all thinkers who are interested in the problems of communication; the media that people build with each other is what they think, what they will talk about, how they will act, and as a consequence, the media influences the society in which the individual lives in, some way (Baldini, 2000: 5). Each technology is a reporter of a new experience and a culture. The transformation of vital practices takes place in this context. This view is supported by John Huzinga's approach of "there had been game before culture". Everything started with a game.

Huizinga defines the game as "while working freedom is continuing outside, the life which we are used to, in other words while the existing life is going on, something that is not real however at the same time can deadly appeal the players to welter in it, something fascinating." (Huizinga, 1950: 13). Jasper Juul describes the game as "a transferable activity which consists rules and has variable and numerical results, with different results are designed with different values, to change the end result the player uses effort, in emotional context it is result oriented" (2005: 36). Game; is an activity that is done by one's own will and regularly at a certain time and place. Border-line-non-serious=is game. According to Turkish Language Institution, game is explained as; entertainment, gambling, performance on the stage, trickery, trap and intrigue, and it is used to spend time with certain rules. In short, game means not real, it has entry and exit in some limitations and it has some rules. The fight against nature of human beings is a game too. With each technical development, the toys of the 
individual are being renewed and individuals are being formed when they use these toys. As a result, the state of game called life is constantly being played by individuals, brought out the technology. In today's environment, virtual reality is a nominee which has become an indispensable part of this environment. In this context, the process between the virtual world and the real world should be examined.

As a result; for the individual, everything is made up of texts. These texts are transmitted to the target via the communication process and the channel or environment is important in these transmissions. This study attempts to discuss the evolution of the environment and the possibilities of this evolution along with the communication process. When the development of the internet is evaluated in the context of technological determinism approach, the digital process which started with bits is now entering the semantic web with the help of intellectual data. With the data, which can think and personalized, in the near future we will not even need to think. "The reality is generated from miniature units, matrices, memory banks and command models and can be replicated unlimited times. It no longer has to be rational, since it is not measured against some ideal or negative examples. In fact, now that it is surrounded by imagination, it is no longer real" (Baudrillard, 2011: 3). In this context, virtual reality $(\mathrm{VR})$ is simulated real and imaginary environments in which we represent ourselves with computer support. This reality environment will replace reality in the future. Unfortunately, the distinction between reality and imagination cannot be done. The past chaos between analog and digital can be given as an example to this. An analog technology has been converted to digital, but electrical devices can sometimes be expressed as digital today. As Toffler points out, our technology power is increasing, but we are unaware of the increasing side effects and possible hazards of it. As a result, according to Morozov, everyone wearing glasses is one way or another is a cyborg. In the future there will be no definite line between reality and virtual reality. In the future the combination of reality and virtual reality will be a hybrid structure.

\section{References}

[1] Artut, S (2014) Teknoloji-Insan Birlikteliği. İstanbul: Ayrıntı Yayınları.

[2] Baudrillard J (2016) Simülakrlar ve Simülasyon. Ankara: Doğu Batı Yayınları.

[3] Bauman Z (1998) Globalization: The Human Consequences. Cambrige: Polity Press; Oxford: Blackwell Publishers Ltd.

[4] Bauman Z (2009) Does Ethics have a Chance in a World of Consumers?. Cambrige and London: Harvard University Press.

[5] Bauman Z (2010) 44 Letters from the Liquid Modern World. Cambrige and Malden: Polity Press.

[6] Bostan B (2007) Sanal Gerçeklikte Etkileşim. Doktora Tezi, Marmara Üniversitesi, İstanbul.

[7] Castells M (1996) The Rise of the Network Society Vol.1 of The Information Age: Economy, Society and Culture. Oxford: Blackwell.

[8] Castells M (2008) Ağ Toplumunun Yükselişi. İstanbul: Bilgi Üniversitesi Yayınları.

[9] Chayko M (2017) Superconnected: The Internet, Digital Media, \&Techno-Social Life. London: Sage Publications.

[10] Ellul J (2003) Teknoloji Toplumu. İstanbul: Bakış Yayınları.

[11] Fiske J (2014) İletişim Çalışmalarına Giriş. Ankara: Pharmakon.

[12] Fuchs C (2014) Social Media: A Critical Introduction. Great Britain: Sage.

[13] Fuchs P \& Moreau G \& Guitton P (Editors) (2011) Virtual Reality: Concepts and Technologies. New York: CRC Press.

[14] Grady S (2003) Virtual Reality: Simulating and Enchancing the World with Computers, New Edition. New York: Facts On File Science Library

[15] Güngör N (2013) İletişim Kuramlar ve Yaklaşımlar. Ankara: Siyasal Kitabevi.

[16] Jacques E (1964) The Technological Society. New York: Vintage Books.

[17] Jenkins H (2006) Convergence Culture. New York: New York University Press.

[18] Kelly K (2010) What Technology Wants. New York: Penguin Books.

[19] Linowes J (2015) Unity Virtual Reality Projects. Birmingham: Packt Publishing.

[20] McLuhan M and Fiore Q (1967) The Medium is the Message. New York: Bantam Books.

[21] Sherman W \& Craig A (2003) Understanding Virtual Reality. San Francisco: Morgan Kaufmann Publishers.

[22] Yengin D (2014) Yeni Medya ve Dokunmatik Toplum. İstanbul: Derin Yayınları. 